\title{
Determination of 17 $\alpha$-Methyltestosterone in Freshwater Samples of Tilapia Farming by High Performance Liquid Chromatography
}

\author{
Isabel R. Barbosa ${ }^{1}$, Sara Lopes ${ }^{2}$, Rhaul Oliveira ${ }^{3}$, Inês Domingues ${ }^{3}$, \\ Amadeu M. V. M. Soares ${ }^{3}$, António J. A. Nogueira ${ }^{3}$ \\ ${ }^{1}$ Centre for Pharmaceutical Studies, Faculty of Pharmacy, University of Coimbra, Coimbra, Portugal \\ ${ }^{2}$ Faculty of Pharmacy, University of Coimbra, Coimbra, Portugal \\ ${ }^{3}$ Department of Biology \& CESAM, University of Aveiro, Aveiro, Portugal \\ Email: ibarbosa@ff.uc.pt
}

Received February 1, 2013; revised March 29, 2013; accepted April 19, 2013

Copyright (C) 2013 Isabel R. Barbosa et al. This is an open access article distributed under the Creative Commons Attribution License, which permits unrestricted use, distribution, and reproduction in any medium, provided the original work is properly cited.

\begin{abstract}
$17 \alpha$-methyltestosterone is used to induce the sex reversal of Tilapia $s p$. to obtain cultures mono-sex to an economically viable. This practice may lead to environmental contamination and problems in human health. Therefore methods need to be developed to detect residues of $17 \alpha$-methyltestosterone in aqueous matrices. A simple high-performance liquid chromatographic method using ultraviolet detection $(245 \mathrm{~nm})$ and testosterone as internal standard has been developed for the monitoring $17 \alpha$-methyltestosterone in freshwater samples of tilapia aquaculture. The method described involves limited sample preparation as it includes a filtration followed by a single solid-phase extraction step using C18 cartridge. Validation data indicated that the HPLC-UV method for $17 \alpha$-methyltestosterone determination in the concentration range of $50-2000 \mu \mathrm{g} / \mathrm{L}$ provided good linearity, sensitivity, accuracy and precision. Method performance was efficiently applied to monitoring the freshwater samples of fish ponds and the surrounding aquatic channels.
\end{abstract}

Keywords: 17 $\alpha$-Methyltestosterone; High Performance Liquid Chromatography; Environment; Tilapia Farming

\section{Introduction}

One of the most cultivated fishes of freshwater in many developing countries is the Nile tilapia (Oreochromis niloticus). Oreochromis species are characterised by a precocious sexual maturity and a high reproductive efficacy, resulting in over population in ponds. To overcome these negative aspects, tilapia culture has traditionally involved all-male populations. The most common method for producing monosex populations (all-male) is the sex reversal of larvae with the use of feeds containing synthetic sex hormones for 21 days. $17 \alpha$-methyltestosterone (MT), 17 $\beta$ hydroxy-17 $\alpha$-methylandrost-4-ene-3-one (Figure 1), is a synthetic anabolic androgenic steroid, commonly used in newly hatched tilapia fry for sex reversal at a concentration of $60 \mathrm{mg}$ per one kilogram of feed [1-3].

Although it was shown that the use of hormone does not result in the accumulation of residues in tissues of fish treated $[4,5]$ there are still concerns about their release into the environment and the reaction of consumers.

Since it is very common to overfeed the fry, residual

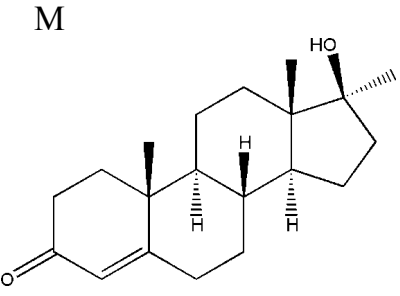

17-Methyltestosterone (MT, I)

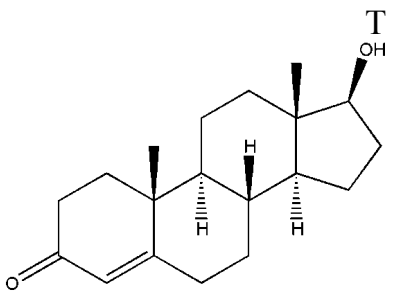

Testosterone (T, II)
Figure 1. Molecular structure of $17 \alpha$-methyltestosterone (MT, I) and internal standard (testosterone, T, II).

in the MT-impregnated food from the masculinizing process may accumulate in the ponds and be released into the receiving water body when the pond water is released or when the ponds are cleaned. The residual MT from uneaten and unmetabolized MT-impregnated food remains in the ponds and, if released, it can contaminate the environment around the discharge points. MT is an endocrine disrupter at part per billion levels $[6,7]$ and can 
interfere with normal functions of the reproductive systems of humans and animals.

Several high performance liquid chromatography (HPLC) and liquid chromatography-mass spectrometry (LC-MS) methods have been reported for the analysis of MT in various biological matrices and pharmaceutical preparations [8-17]. To our knowledge, the analysis of MT in aqueous matrices has not been performed. The purpose of this work was to develop a simple, effective and sensitive method for determination of MT residues in aqueous matrices. The work presented here used HPLC with UV detector for the determination of MT following a solid-phase extraction (SPE). This method was validated and used to monitor MT residues in water samples of tilapias farming.

\section{Experimental}

\subsection{Chemicals and Materials}

All reagents used during the extraction and analysis were analytical reagent grade. $17 \alpha$-methyltestosterone $(17 \beta$ Hydroxy-17 $\alpha$-methyl-4-androsten-3-one, CAS n: 58-18-4, purity $97.7 \%)$ and internal standard, testosterone $(17 \alpha-$ hydroxyandrost-4-en-3-one, CAS no: 58-22-0, purity 99\%), were purchased from Sigma-Aldrich (St. Louis, MO, USA). Methanol, acetonitrile and ethanol were all HPLCgrade and purchased from Merck (Darmstadt, Germany). Ultrapure water was obtained in the laboratory by Milli$\mathrm{Q}^{\circledR}$ system (Millipore Corporation, Milford, MA, USA). The cartridges used for, SPE were Discovery ${ }^{\circledR}$ DSC-18 $\mu \mathrm{m}, 6 \mathrm{~mL}, 500 \mathrm{mg}$, (Supelco, USA).

\subsection{Apparatus and Chromatographic Conditions}

The method was developed on a Shimadzu HPLC system LC-2010C HT with quaternary pumps, autosampler, column oven, UV detector, degasser, and controlled by Shimadzu LC Solutions ${ }^{\circledR}$ software. The chromatographic separation was achieved with a $\mathrm{C}_{18}$ reverse-phase (RP- $\left.\mathrm{C}_{18}\right)$ column (ACE, $5 \mu \mathrm{m}$ particle size, $250 \times 4.6 \mathrm{~mm}$ ) at $25^{\circ} \mathrm{C}$. All injections were performed automatically using $20 \mu \mathrm{l}$ loop on autosampler. Detection of analyte was carried out using UV detector at $245 \mathrm{~nm}$. The analyte were separated by running a mobile phase consisted of ace-tonitrile and ultrapure water $(45: 55, \mathrm{v} / \mathrm{v})$ at a flow rate of 1 $\mathrm{mL} \cdot \min ^{-1}$.

\subsection{Method and Sample Preparation}

\subsubsection{Sample Collection and Preparation}

A total of twenty-six surface water samples were collected in $200 \mathrm{~mL}$ PET bottles at different fish ponds and the surrounding aquatic channels. The water samples were frozen at $-20^{\circ} \mathrm{C}$. The freshwater samples of Tilapia farming were previously defrosted, spiked appropriate amounts of with internal standard (testosterone, IS), filtered through $0.2 \mu \mathrm{m}$ membrane filter (Schleicher \& Schuell) and then extracted by solid phase extraction (SPE).

\subsubsection{Standard Solutions}

Individual stock standard solutions $(100 \mathrm{mg} / \mathrm{L})$ were prepared in methanol. The working standard solutions of $17 \alpha-$ methyltestosterone were prepared through appropriated dilutions to obtain concentrations between $50-2000 \mu \mathrm{g} / \mathrm{L}$. The working standard solutions of testosterone were prepared to have the concentration of the $500 \mu \mathrm{g} / \mathrm{L}$. The stock standard solutions were stored at $-20^{\circ} \mathrm{C}$ and the working standard solutions were stored at $4^{\circ} \mathrm{C}$ for 6 months.

\subsubsection{Extraction and Clean-Up}

The cartridge was preconditioned sequentially with $5 \mathrm{~mL}$ of acetonitrile followed by same volume of Milli-Q water. The water samples were loaded on the preconditioned cartridge under vacuum. The washing step was performed with Milli-Q water. Then the cartridge was eluted with $5 \mathrm{~mL}$ of ethanol at a flow rate of $2 \mathrm{~mL} / \mathrm{min}$. The eluate was evaporated to dryness at $37^{\circ} \mathrm{C}-40^{\circ} \mathrm{C}$ and the residue was redissolved in $200 \mu \mathrm{L}$ of acetonitrile. The volume of eluate injected was $20 \mu \mathrm{L}$.

\section{Results and Discussion}

\subsection{Optimization of HPLC Conditions}

Prior to the analytical determination of $17 \alpha$-methyltestosterone with reversed phase HPLC/UV-Vis method the UV region was scanned to obtain a shared absorption wavelength for $17 \alpha$-methyltestosterone and testosterone as IS. As a result, $245 \mathrm{~nm}$ was selected as the optimum wavelength for simultaneous determination of these compounds. Feasibility of different solvent systems such as acetonitrile-water and methanol-water mixtures in different compositions, pumped at different flow rates (in the range of $0.5-1.5 \mathrm{ml} / \mathrm{min}$ ) at different column oven temperatures (in the range of $25^{\circ} \mathrm{C}-35^{\circ} \mathrm{C}$ ) were evaluated. Best results were obtained using acetonitrile-water in the ratio of $45: 55, \mathrm{v} / \mathrm{v}$ at a flow rate of $1 \mathrm{~mL} \cdot \mathrm{min}^{-1}$ with a column oven temperature at $25^{\circ} \mathrm{C}$ on the analysis of both steroids. The chromatogram in the Figure 2(a) shows the separation of analytes obtained by the proposed method.

\subsection{Optimization of Extraction and Clean-Up}

The clean-up efficiencies for Discovery ${ }^{\circledR}$ DSC-18 $\mu \mathrm{m}, 6$ $\mathrm{mL} / 500 \mathrm{mg}$ cartridges were studies by adjusting the following parameters: the solvents used in the washing steps, the eluent solvents, and the volumes for eluting $17 \alpha$ methyltestosterone from the cartridge. The polymeric 


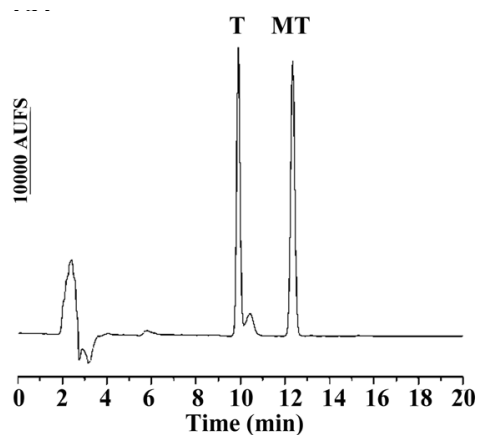

(a)

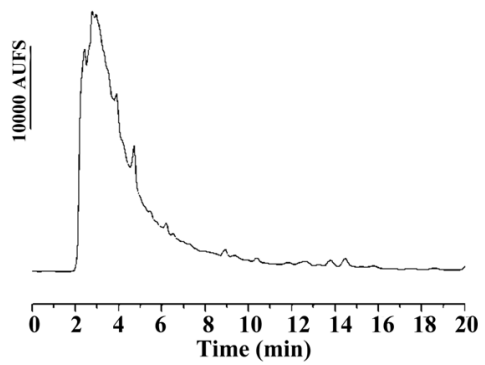

(b)

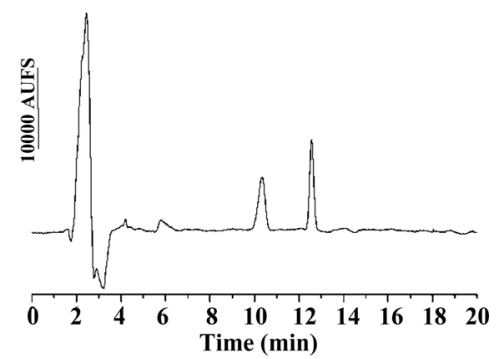

(c)

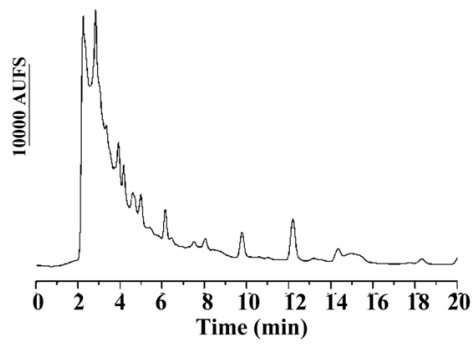

(d)

Figure 2. (a) (b) (c) (d) Chromatogram of (a) Standard solution with MT and T (IS) with $600 \mu \mathrm{g} / \mathrm{L}$ respectively; (b) Water blank sam- ple; (c) Spiked water blank with 100 $\mu \mathrm{g} / \mathrm{L}$ of MT and PI; (d) Freshwater sample of tilapia aquaculture containing $617.4 \mu \mathrm{g} / \mathrm{L}$ of MT.

reversed-phase sorbent showed no effect in the analyte. The cartridges were washed with $5 \mathrm{ml}$ of Milli-Q water to obtain clean blank chromatograms without interferences. The elution of $17 \alpha$-methyltestosterone was study with different solvents and volumes. Thus our results show that $5 \mathrm{~mL}$ of ethanol is necessary and sufficient to elute all $17 \alpha$-methyltestosterone from cartridge. This method was therefore applied to monitoring $17 \alpha$-methyltestosterone in freshwater samples of fish ponds and the surrounding aquatic channels.

\subsection{Method Validation}

In the validation procedure of the analytical method, the following criteria were considered: sensitivity; linearity; recovery; precision and evaluation of the matrix effect.

\subsubsection{Linearity}

The calibration curves were prepared using linear regression analysis and gave good fits over the range 50 - 2000 $\mu \mathrm{g} / \mathrm{L}$. The mean regression coefficients $\left(\mathrm{R}^{2}\right)$ were 0.999 for $17 \alpha$-methyltestosterone.

\subsubsection{Stability Studies}

The stability of standard solutions and sample extracts was evaluated. The stock standard solutions were stored at $-20^{\circ} \mathrm{C}$ and analysed during one-month period, and the working standard solutions stored at $4{ }^{\circ} \mathrm{C}$ were analysed during a one-week period. We did not observe any degradation of $17 \alpha$-methyltestosterone and testosterone in this study period. The stability of $17 \alpha$-methyltestosterone during sample storage at $-20^{\circ} \mathrm{C}$ was tested during one week, and no degradation was observed.

\subsubsection{Limit of Quantification and Accuracy}

The limit the quantification, calculated according to the lower concentration that provides repeatabilities lower than $20 \%$, was $58.3 \mu \mathrm{g} / \mathrm{L}$ for $17 \alpha$-methyltestosterone. The limit of detection it was $19 \mu \mathrm{g} / \mathrm{L}$ at a signal-to-noise of $3: 1$.

In order to verify the absence of potential interfering substances around the retention time of $17 \alpha$-methyltestosterone and testosterone, water blank samples $(\mathrm{n}=5)$ were analysed in order to assess the specificity of the method. No interferences were observed in the region of interest where the $17 \alpha$-methyltestosterone and testosterone were eluted (Figure 2(b)).

The results demonstrate that real sample matrices had no effect on the performance of the proposed method, which is therefore suitable for analysis of trace levels of $17 \alpha$-methyltestosterone in surface water of fish ponds and the surrounding aquatic channels.

The accuracy of the method was studied by spiking water samples at three fortification levels (100, 600 and $2000 \mu \mathrm{g} / \mathrm{L}$ ). Figure 2(c) represents the chromatogram obtained for fortification assay.

Within-day accuracy and precision data were determined by analysing, on the same day, three replicates of spiked samples at three levels, and one blank (to check the interferences). The between-day accuracy and precision were also determined by extracting batches of three fortification levels and analysing them on the five con- 
Table 1. Recovery, intra-day and inter-day precision and accuracy $(n=5)$.

\begin{tabular}{ccccccc}
\hline \multirow{2}{*}{$\begin{array}{c}\text { Spike level } \\
(\mu \mathrm{g} / \mathrm{L})\end{array}$} & \multicolumn{2}{c}{ Recovery } & \multicolumn{2}{c}{ Intra-day } & \multicolumn{2}{c}{ Inter-day } \\
\cline { 2 - 7 } & Mean $(\%)$ & $\mathrm{CV}(\%)$ & Precision $(\mathrm{CV} \%)$ & Accuracy $(\%)$ & Precision $(\mathrm{CV} \%)$ & Accuracy $(\%)$ \\
\hline 100 & $103.9 \pm 1.62$ & 0.04 & 0.04 & $103.7 \pm 3.8$ & 0.04 & $105.1 \pm 3.8$ \\
600 & $99.3 \pm 0.83$ & 0.008 & 0.04 & $99.2 \pm 4.2$ & 0.02 & $98.0 \pm 1.9$ \\
2000 & $93.1 \pm 1.25$ & 0.01 & 0.03 & $93.0 \pm 3.15$ & 0.04 & $94.6 \pm 4.2$ \\
\hline
\end{tabular}

secutive days. Accuracy and intra-day and inter-day precision are shown in Table 1. Recoveries for the lower fortification level were generally greater than $100 \%$ for $17 \alpha$-methyltestosterone. For the three fortification levels, the relative standard deviation for all fortification levels on each day for $17 \alpha$-methyltestosterone was less than $12 \%$, demonstrating good method precision.

\subsection{Application of the Proposed Method}

A total of twenty-six samples of water were analysed under the conditions described, and 17 $\alpha$-methyltestosterone were detected in six samples at level higher than the LOQ in the concentration of $59.9>2000 \mu \mathrm{g} / \mathrm{L}$. Figure 2(d) represents the chromatogram obtained with one of water sample fish ponds analysed.

\section{Conclusion}

The monitoring of $17 \alpha$-methyltestosterone residues is an important issue in order to avoid possible residues in water systems release into the environment from Tilapia farming. In the present study, we developed a simple HPLC method to identify and quantify trace levels of release into the environment in real environmental surface water samples from one of Tilapia farming of Thailand. The use of a RP-column with UV detection allows the rapid and sensitive analysis required for this type of analysis. The proposed HPLC method was proved to be convenient and effective for monitoring the waters in the fish ponds (MT unmetabolized and surplus food with MT) and the waters at different points of discharge in the farming.

\section{REFERENCES}

[1] W. L. Gale, M. S. Fitzpatrick, M. Lucero, W. M. Contreras-Sanchez and C. B. Schreck, "Masculinization of Nile Tilapia (Oreochromis niloticus) by Immersion in Androgens Original," Aquaculture, Vol. 178, No. 3-4, 1999, pp. 349-357. doi:10.1016/S0044-8486(99)00136-2

[2] J. A. Beardmore, G. C. Mair and R. I. Lewis, "Monosex Male Production in Finfish as Exemplified by Tilapia: Applications, Problems, and Prospects," Aquaculture, Vol. 197, No. 1-4, 2001, pp. 283-301. doi:10.1016/S0044-8486(01)00590-7

[3] T. J. Pandian and S. G. Sheela, "Hormonal Induction of
Sex Reversal in Fish," Aquaculture, Vol. 138, No. 1-4, 1995, pp. 1-22. doi:10.1016/0044-8486(95)01075-0

[4] J. S. Abucay and G. C. Mair, "Hormonal Sex Reversal of Tilapias: Implications of Hormone Treatment Application in Closed Water Systems," Aquaculture Research, Vol. 28, No. 11, 1997, pp. 841-845. doi:10.1111/j.1365-2109.1997.tb01008.x

[5] L. R. Curtis, F. T. Diren, M. D. Hurley, W. K. Seim and R. A. Tubb, "Disposition and Elimination of $17 \alpha$-Methyltestosterone in Nile Tilapia (Oreochromis niloticus)," Aquaculture, Vol. 99, No. 1-2, 1991, pp. 193-201. doi:10.1016/0044-8486(91)90298-L

[6] L. Andersen, R. Goto-Kazeto, J. M. Trant, J. P. Nash, B. Korsgaard and P. Bjerregaard, "Short-Term Exposure to Low Concentrations of the Synthetic Androgen Methyltestosterone Affects Vitellogenin and Steroid Levels in Adult Male Zebrafish (Danio rerio)," Aquatic Toxicology, Vol. 76, No. 3-4, 2006, pp. 343-352. doi:10.1016/j.aquatox.2005.10.008

[7] S. Wason, G. Pohlmeyer-Esch, C. Pallen, X. Palazzi, G. Espuña and R. Bars, "17 $\alpha$-Methyltestosterone: 28-Day Oral Toxicity Study in the Rat Based in the 'Enhanced OECD Test Guideline 407' to Detect Endocrine Effects," Toxicology, Vol. 192, No. 2-3, 2003, pp. 119-137. doi: $10.1016 / \mathrm{S} 0300-483 \mathrm{X}(03) 00265-8$

[8] D. Teichert-Coddington, B. Manning, J. C. Eya and D. Brock, "Concentration of $17 \mu$-Mehtyltestosterone in Hormone-Treated Feed: Effects of Analytical Technique, Fabrication, and Storage Temperature," Journal of the World Aquaculture Society, Vol. 31, No. 1, 2000, pp. 42-50. doi:10.1111/j.1749-7345.2000.tb00696.x

[9] W. Van Thuyne and F. T. Delbeke, "Validation of a GCMS Screening Method for Anabolizing Agents in Aqueous Nutritional Supplements," Journal of Chromatography Science, Vol. 43, No. 1, 2005, pp. 2-6.

[10] C. A. Goudie, "Extraction of a Synthetic Androgen from Fish Muscle and Quantitation by High Performance Liquid Chromatography," Steroid, Vol. 44, No. 3, 1984, pp. 241-252. doi:10.1016/0039-128X(84)90005-9

[11] E. A. I. Daeseleire, A. De Guesquière and C. H. Van Peteghem, "Multiresidue Analysis of Anabolic Agents in $\mathrm{Mu}-$ scle Tissues and Urines of Cattle by GC-MS," Journal of Chromatography Science, Vol. 30, No. 10, 1992, pp. 409414.

[12] B. L. Lampert and J. T. Stewart, "Determination of Anabolic Steroids and Zeranol in Human Serum by Isocratic Reverse Phase HPLC on Silica," Journal of Liquid Chromatography, Vol. 12, No. 16, 1989, pp. 3231-3249.

[13] M. H. Blokland, H. J. van Rossum, H. A. Herbold, S. S. 
Sterk, R. W. Stephany and L. A. Van Ginkel, "Metabolism of Methyltestosterone, Norethandrolone and Methylboldenone in a Heifer," Analytica Chimica Acta, Vol. 529, No. 1-2, 2005, pp. 317-323.

doi:10.1016/j.aca.2004.10.064

[14] P. Regal, C. Nebot, B. I. Vásquez, A. Cepeda and C. A. Fente, "Determination of the Hormonal Growth Promoter $17 \alpha$-Methyltestosterone in Food-Producing Animals: Bovine Hair Analysis by HPLC-MS/MS," Meat Science, Vol. 84, No. 1, 2010, pp. 196-201. doi:10.1016/i.meatsci.2009.08.047

[15] R. Chiba and Y. Ishii, "Simultaneous Determination of Yohimbine Hydrochloride, Strychnine Nitrate and Methyltestosterone by Ion-Pair High-Performance Liquid Chro- matography," Journal of Chromatography A, Vol. 588, No. 1-2, 1991, pp. 344-347. doi:10.1016/0021-9673(91)85044-G

[16] A. Cappiello, G. Famiglini, F. Mangani, P. Palma and A. Siviero, "Nano-High-Performance Liquid Chromatography-Electron Ionization Mass Spectrometry Approach for Environmental Analysis," Analytica Chimica Acta, Vol. 493, No. 2, 2003, pp. 125-136. doi:10.1016/S0003-2670(03)00868-7

[17] A. Marwah, P. Marwah and H. Lardy, "Development and Validation of a High Performance Liquid Chromatography Assay for $17 \alpha$-Methyltestosterone in Fish Feed," Journal of Chromatography B, Vol. 824, No. 1-2, 2005, pp. 107-115. doi:10.1016/j.jchromb.2005.07.005 